\title{
Prognostic values of aldehyde dehydrogenase I isoenzymes in ovarian cancer
}

This article was published in the following Dove Press journal:

OncoTargets and Therapy

4 April 2016

Number of times this article has been viewed

Yu-mei Ma'

Shan Zhao ${ }^{2}$

'Department of Pathology, ${ }^{2}$ Department of Cancer Second Division, The Second Hospital of Hebei Medical University, Shijiazhuang City, People's Republic of China
Correspondence: Yu-mei Ma Department of Pathology, The Second Hospital of Hebei Medical University, 2I5 Heping West Road, Shijiazhuang City 050000, People's Republic of China $\mathrm{Tel}+8603$ I I 8704690 I Emailyumeimamd@I63.com

\begin{abstract}
Aldehyde dehydrogenase 1 (ALDH1) activity has been used as a functional stem cell marker to isolate cancer stem cells in different cancer types, including ovarian cancer. However, which ALDH1's isoenzymes are contributing to ALDH1 activity in ovarian cancer remains elusive. In addition, the prognostic value of an individual ALDH1 isoenzyme in ovarian cancer is not clear. Thus, we accessed the prognostic value of ALDH1 isoenzymes in ovarian cancer patients through the "Kaplan-Meier plotter" online database, which can be used to determine the effect of the genes on ovarian cancer prognosis. We found that high mRNA expression of five ALDH1 isoenzymes, such as ALDH1A1, ALDH1A2, ALDH1A3, ALDH1B1, and ALDH1L1, was not correlated with overall survival (OS) for all 1,306 ovarian cancer patients. In addition, all five of the ALDH1 isoenzymes' high mRNA expression was found to be uncorrelated with OS in serous cancer or endometrioid cancer patients. However, ALDH1A3's high mRNA expression is associated with worse OS in grade II ovarian cancer patients, hazard ratio (HR) 1.53 (1.14-2.07), $P=0.005$. ALDH1A2's high mRNA expression is significantly associated with worse OS in TP53 wild-type ovarian cancer patients, HR 2.86 (1.56-5.08), $P=0.00036$. In addition, $A L D H 1 A 3$ 's high mRNA expression is significantly associated with better OS in TP53 wild-type ovarian cancer patients, HR 0.56 (0.32-1.00), $P=0.04$. Our results indicate that although ALDH1 isoenzyme mRNA might not be a prognostic marker for overall ovarian cancer patients, some isoenzymes, such as $A L D H 1 A 2$ and $A L D H 1 A 3$, might be a good prognostic marker for some types of ovarian cancer patients.
\end{abstract}

Keywords: ALDH1, cancer stem cell, prognosis, KM plotter, hazard ratio

\section{Introduction}

Ovarian cancer ranks fourth among the causes of cancer deaths in women and is the seventh most common cancer in women. It was predicted that $>14,030$ women will die of ovarian cancer and $\sim 22,240$ new cases of ovarian cancer were diagnosed in the USA in 2013. ${ }^{1}$ Most ovarian malignancies have epithelial origins ${ }^{2}$ and are further grouped into histological types as follows: serous, mucinous, clear cell, endometrioid, carcinosarcoma, transitional cell tumors (Brenner tumors), mixed epithelial tumor, undifferentiated carcinoma, and others. Despite advances in early diagnosis, cytotoxic chemotherapy, radical cure operation, and targeted therapeutic treatment, there are still $\sim 85 \%$ of ovarian cancer patients who would develop recurrent disease, after achieving a full remission following the first-line therapy. ${ }^{3,4}$ Thus, the identification on the mechanism of initiation, progression, as well as investigation of differential diagnostic prognostic marker and potential drug target, is still needed and will help to provide better prognosis and individualized treatments.

Elevated aldehyde dehydrogenase 1 (ALDH1) activity has been detected in the stem cell populations of human acute myeloid leukemia, multiple myeloma, and a number 
of solid tumors. ${ }^{5-9}$ A number of reports have also shown that increased ALDH1 expression was detected in some ovarian cancer cell lines ${ }^{10-14}$ and ovarian tumor tissues. ${ }^{11,13-20}$ Therefore, examination of ALDH1 activity shows promising results as a universal marker for both normal and malignant stem cell populations, including ovarian cancer. The ALDH1 family is composed of enzymes that contribute to the oxidation of retinol to retinoic acid in stem cell differentiation; ${ }^{21-23}$ which individual ALDH1's isoenzyme is a major isoenzyme in ovarian cancer and contribute to ALDH1 activity has not been determined. Furthermore, the prognostic role of individual ALDH1 isoenzyme in ovarian cancer remains elusive. An online Kaplan-Meier plotter (KM plotter), which can be used to determine the effect of the genes on ovarian cancer prognosis, generated data from Gene Expression Omnibus (www.ncbi.nlm.nih.gov/geo/) database. KM plotter database was initially established using data from a group of 1,809 breast cancer patients. ${ }^{24,25}$ Later, this database also included gene expression data from a total of 1,306 ovarian cancer patients. ${ }^{26}$ Thus, KM plotter can be utilized for the analysis of individual genes with clinical results to total survival of patients. By using KM plotter so far, a number of prognostic markers have been identified and/or validated in breast cancer, ${ }^{27-37}$ lung cancer, ${ }^{37-40}$ as well as ovarian cancer. ${ }^{37,41,42}$ In this study, we determined the prognostic role of individual $A L D H 1$ isoenzymes in human ovarian cancer patients using KM plotter database.

\section{Materials and methods}

We used the KM plotter online database ${ }^{24}$ to determine the relevance of individual $A L D H 1$ members' messenger RNA (mRNA) expression to overall survival (OS) of ovarian cancer patients. The Hebei Medical University Institutional Review Board deemed this retrospective study exempt from ethical approval and patient consent due to patient data being de-identified. Currently, the database includes breast cancer, ${ }^{24}$ lung cancer, ${ }^{38}$ gastric cancer, as well as ovarian cancer $^{26}$ data. Ovarian cancer patients in the database were identified from the cancer Biomedical Informatics Grid (http://cabig.cancer.gov/, microarray samples are published in the caArray project), on The Cancer Genome Atlas (http://cancergenome.nih.gov), and the Gene Expression Omnibus (http://www.ncbi.nlm.nih.gov/geo/) ovarian cancer datasets. ${ }^{26}$ They provided clinical data, including age, histology, grade, stage, TP53 mutation status, and applied chemotherapy for all patients in WinStat 2013. The ovarian cancer patients were followed up for 20 years. The database was integrated using gene expression data and survival information of 1,306 ovarian cancer patients. Briefly, five $A L D H 1$ sub-members ( $A L D H 1 A 1, A L D H 1 A 2, A L D H 1 A 3, A L D H 1 B 1$, and $A L D H 1 L 1)$ were entered into the database (http://kmplot. com/analysis/index.php?p=service\&cancer=ovar) to obtain Kaplan-Meier survival plots. Certain gene mRNA expression above or below the median separates the cases into high expression and low expression. Hazard ratio (HR), 95\% confidence intervals, and logrank $P$ were calculated and displayed on the webpage.

\section{Results}

The ALDH1 family is composed of six submembers. As previously indicated, ${ }^{35}$ only ALDH1L2 among all the six ALDH1 isoenzymes was not found in www.kmplot.com, probably due to its low expression in cancer tissues. We first accessed the prognostic value of $A L D H 1 A 1$ 's mRNA expression. The desired Affymetrix ID is valid: 212224_at (ALDH1A1). Survival curves are plotted for all patients $(n=1,306$; Figure 1A), for serous cancer patients ( $\mathrm{n}=1,019$; Figure 1B), and for endometrioid cancer patients ( $\mathrm{n}=36$; Figure 1C). $A L D H 1 A 1$ 's high mRNA expression was found to be uncorrelated with OS for all ovarian cancer patients followed for 20 years, HR 1.00 (0.77-0.99), $P=0.98$. In addition, $A L D H 1 A 1$ 's high mRNA expression was also found to be uncorrelated with OS in serous cancer patients, HR $0.96(0.82-1.11), P=0.57$, and in endometrioid cancer patients, HR $0.46(0.17-1.28), P=0.13$.

We then accessed the prognostic value of $A L D H 1 A 2$ 's mRNA expression. The desired Affymetrix ID is valid: 207015_s_at (ALDH1A2). ALDH1A2's high mRNA expression was found to be uncorrelated with OS for all ovarian cancer patients, HR 1.02 (0.89-1.16), $P=0.79$ (Figure 2A). In addition, $A L D H 1 A 2$ 's high mRNA expression was also found to be uncorrelated with OS in serous cancer patients, HR 1.14 (0.98-1.33), $P=0.087$ (Figure 2B), and in endometrioid cancer patients, HR 1.17 (0.44-3.13), $P=0.75$ (Figure 2C).

Figure 3 shows the prognostic value of ALDH1A3's mRNA expression. The desired Affymetrix ID is valid: 203180_at (ALDH1A3). The curves show that ALDH1A3 expression above or below the median does not separate the cases into significantly different prognostic groups in ovarian cancer patients, HR $1.08(0.95-1.24), P=0.22$ (Figure 3A); serous cancer patients, HR 1.13 (0.97-1.31), $P=0.12$ (Figure $3 \mathrm{~B}$ ); or endometrioid cancer patients, HR 0.41 (0.14-1.18), $P=0.086$ (Figure 3C).

Figure 4 shows the prognostic value of $A L D H 1 B 1$ 's mRNA expression. The desired Affymetrix ID is valid: 209646_x_at (ALDH1B1). ALDH1B1's high mRNA expression was found to be uncorrelated with OS for all ovarian cancer patients, $H R$ 1.02 (0.9-1.17), $P=0.74$ (Figure 4A). In addition, $A L D H 1 B 1$ 's 

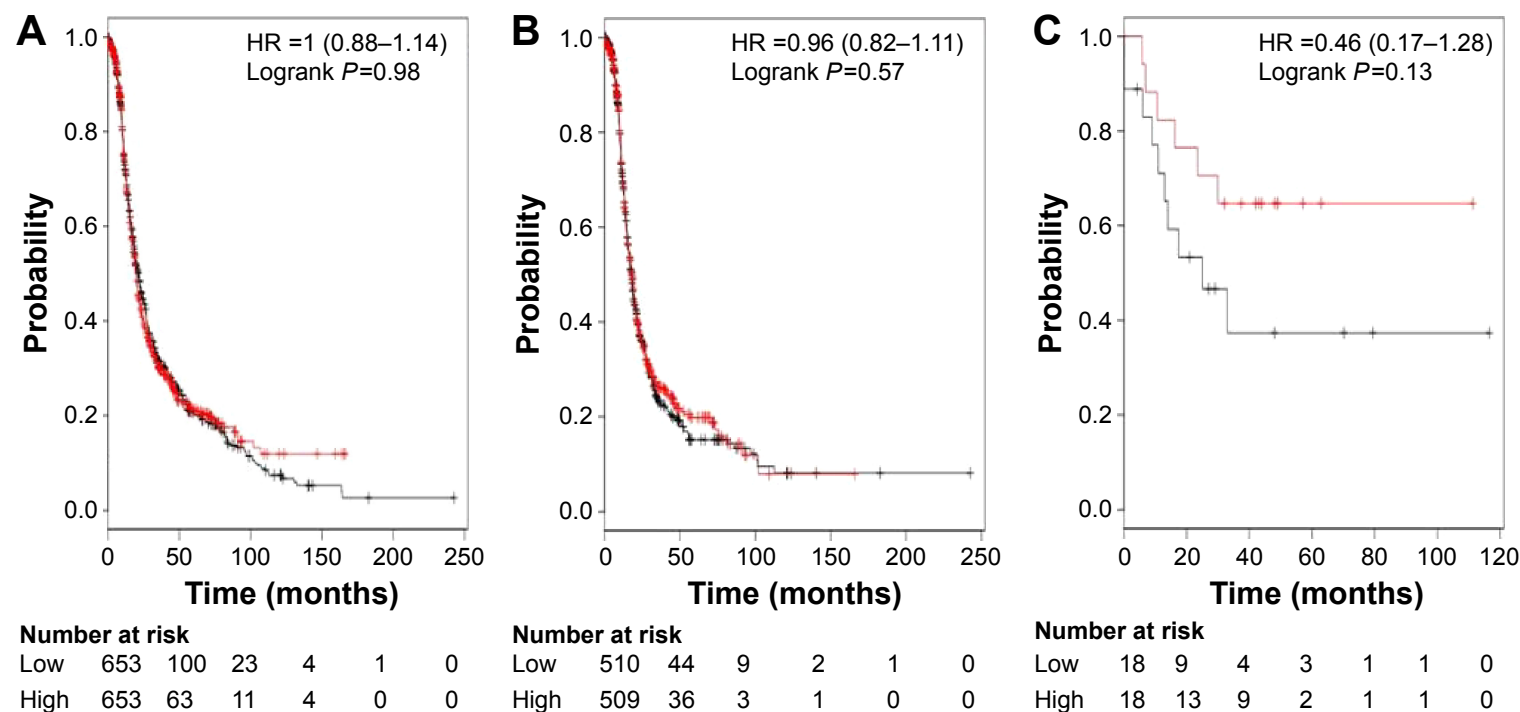

\section{Number at risk}

$\begin{array}{llllllll}\text { Low } & 18 & 9 & 4 & 3 & 1 & 1 & 0 \\ \text { High } & 18 & 13 & 9 & 2 & 1 & 1 & 0\end{array}$

\begin{tabular}{|ll|}
\hline Expression \\
Low
\end{tabular}

Figure I The prognostic value of ALDHIA I expression.

Notes: The desired Affymetrix ID is valid: 2I2224_at (ALDHIAI). Survival curves are plotted for $(\mathbf{A})$ all patients $(\mathrm{n}=\mid, 306),(\mathbf{B})$ serous cancer patients $(\mathrm{n}=\mathrm{I}, 0 \mathrm{I})$, and (C) endometrioid cancer patients $(n=36)$

Abbreviations: ALDHI, aldehyde dehydrogenase I; HR, hazard ratio.

high mRNA expression was also found to be uncorrelated with OS in serous cancer patients, HR 1.11 (0.95-1.29), $P=0.19$ (Figure 4B), and in endometrioid cancer patients, HR 1.2 (0.45-3.2), $P=0.72$ (Figure 4C).
Finally, we accessed the prognostic value of $A L D H 1 L 1$ 's mRNA expression. The desired Affymetrix ID is valid: 205208_at (ALDH1L1). The curves show that ALDH1L1 expression above or below the median does not separate
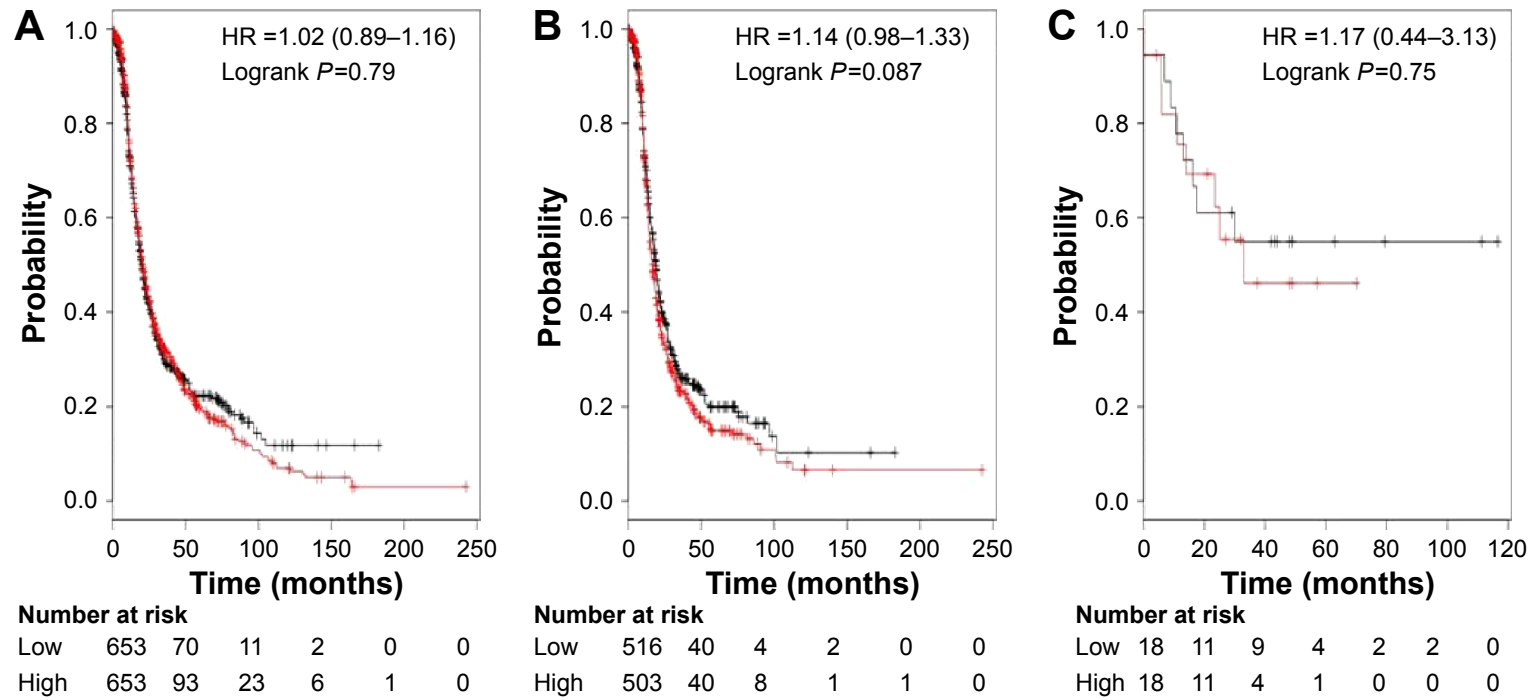

Number at risk

Low 18 11 $11 \quad 9 \quad 4 \quad \begin{array}{llll}2 & 2 & 0\end{array}$

\begin{tabular}{|l|}
\hline Expression \\
\hline
\end{tabular} Low High

Figure 2 The prognostic value of ALDHIA2 expression.

Notes: The desired Affymetrix ID is valid: 207015_s_at (ALDHIA2). Survival curves are plotted for $(\mathbf{A})$ all patients $(\mathrm{n}=1,306)$, $(\mathbf{B})$ serous cancer patients ( $\mathrm{n}=1,019)$, and (C) endometrioid cancer patients $(n=36)$.

Abbreviations: ALDHI, aldehyde dehydrogenase I; HR, hazard ratio. 


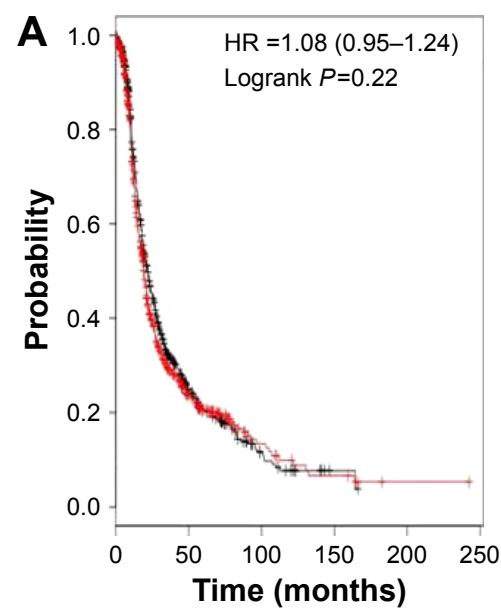

Number at risk

$\begin{array}{llllllll}\text { Low } & 653 & 87 & 18 & 2 & 0 & 0\end{array}$

High $\quad \begin{array}{llllll}653 & 76 & 16 & 6 & 1 & 0\end{array}$
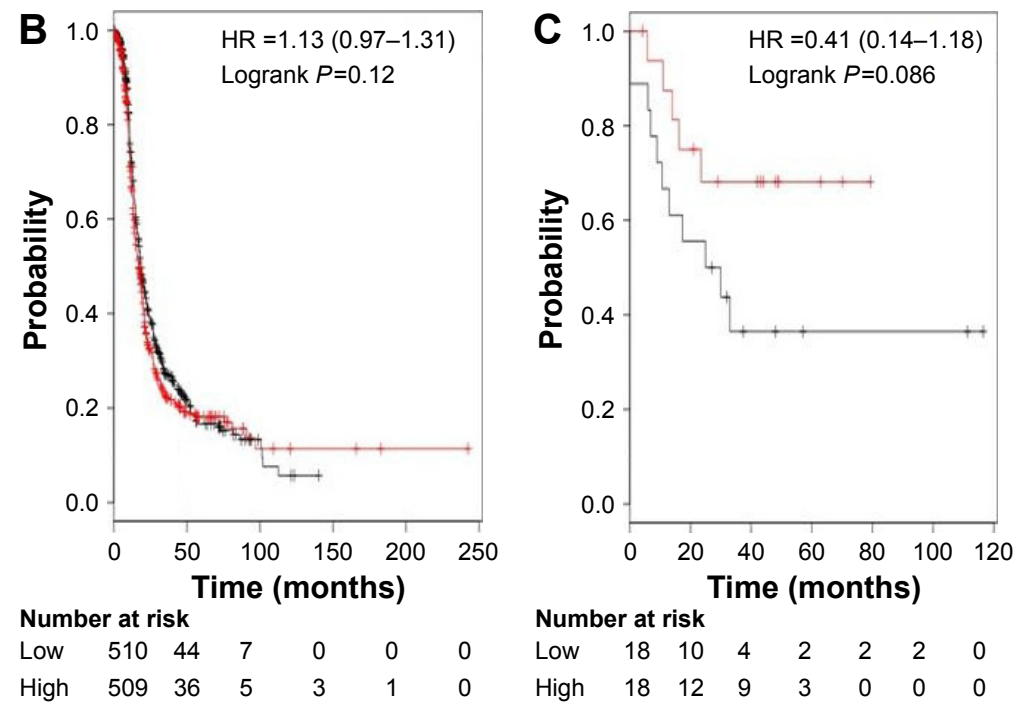

Number at risk

$\begin{array}{llllllll}\text { Low } & 18 & 10 & 4 & 2 & 2 & 2 & 0\end{array}$

$\begin{array}{llllllll}\text { High } & 18 & 12 & 9 & 3 & 0 & 0 & 0\end{array}$

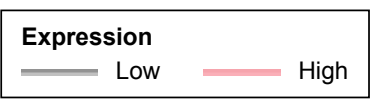

Figure 3 The prognostic value of ALDHIA3 expression.

Notes: The desired Affymetrix ID is valid: 203180 at (ALDHIA3). Survival curves are plotted for $(\mathbf{A})$ all patients $(\mathrm{n}=1,306)$, (B) serous cancer patients (n=I,0I9), and (C) endometrioid cancer patients $(n=36)$.

Abbreviations: ALDHI, aldehyde dehydrogenase I; HR, hazard ratio.

the cases into significantly different prognostic groups in ovarian cancer patients, HR $0.91(0.8-1.04), P=0.17$ (Figure 5A); serous cancer patients, HR $1.04(0.89-1.2)$, $P=0.66$ (Figure 5B); or endometrioid cancer patients, HR 0.59 (0.21-1.62), $P=0.3$ (Figure 5C).
To further access the correlation of individual $A L D H 1$ isoenzymes with other clinicopathological features, we valuated the correlation with pathological grades (Table 1), clinical grades (Table 2), and TP53 mutation (Table 3) of ovarian cancer patients. As observed in Table 1, all the
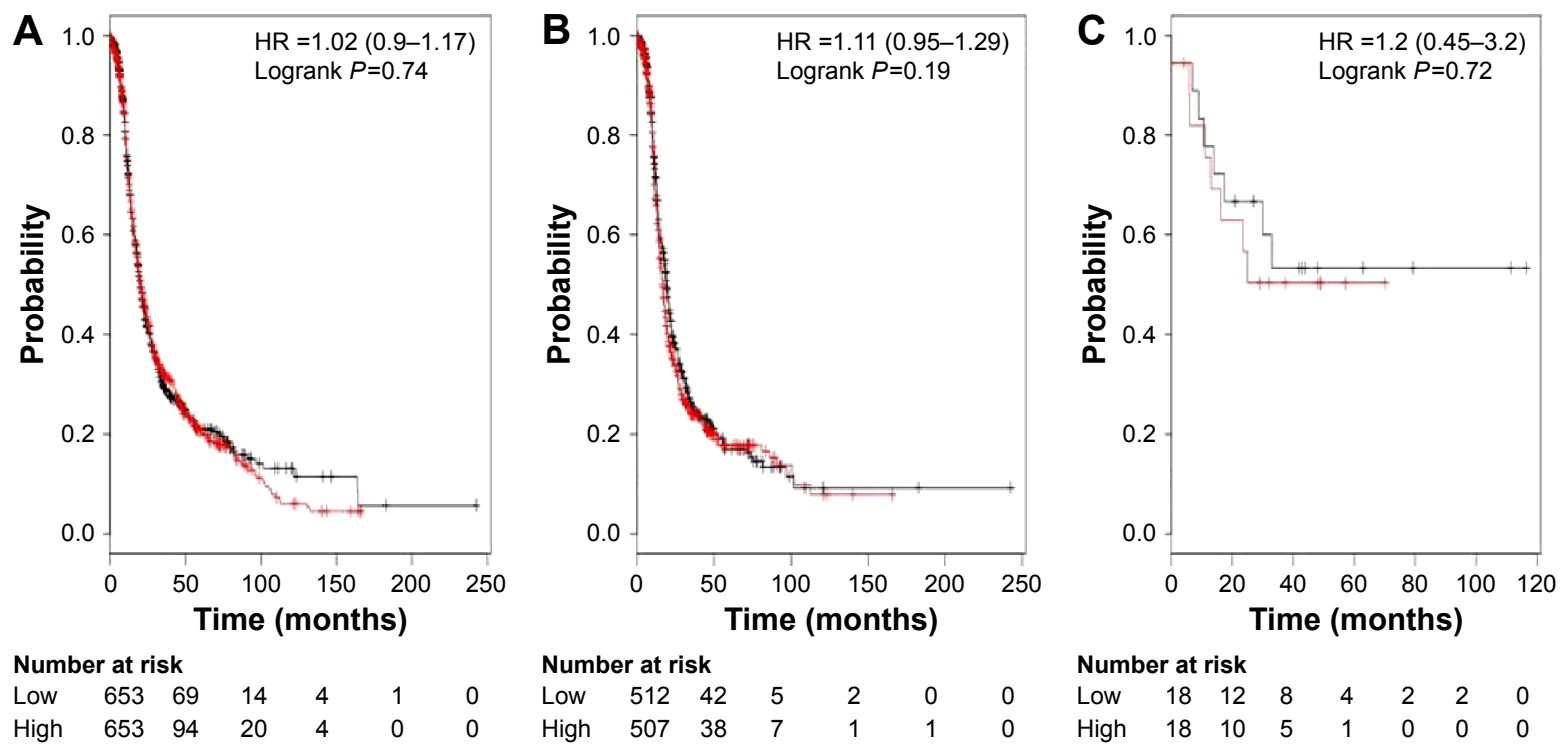

\section{Number at risk}

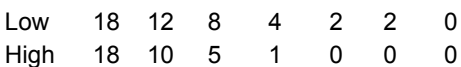

\begin{tabular}{|ll|}
\hline \multicolumn{2}{|c|}{ Expression } \\
Low
\end{tabular}

Figure 4 The prognostic value of $A L D H I B /$ expression.

Notes: The desired Affymetrix ID is valid: 209646_x_at (ALDHIBI). Survival curves are plotted for $(\mathbf{A})$ all patients $(\mathrm{n}=\mathrm{I}, 306)$, $(\mathbf{B})$ serous cancer patients ( $\mathrm{n}=\mathrm{I}, 0 \mathrm{I9})$, and (C) endometrioid cancer patients $(n=36)$.

Abbreviations: ALDHI, aldehyde dehydrogenase I; HR, hazard ratio. 


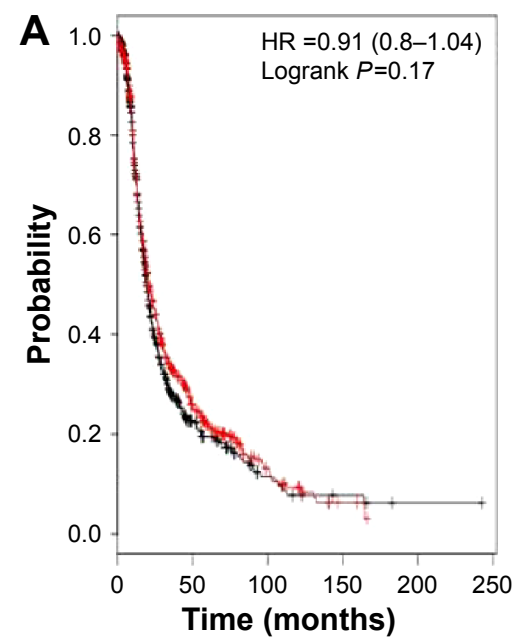

Number at risk

$\begin{array}{lllllll}\text { Low } & 653 & 67 & 13 & 5 & 1 & 0 \\ \text { High } & 653 & 96 & 21 & 3 & 0 & 0\end{array}$

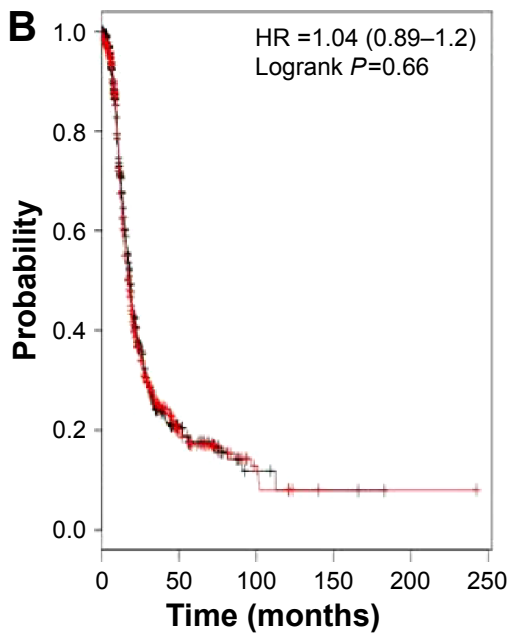

Number at risk

$\begin{array}{lllllll}\text { Low } & 510 & 40 & 4 & 2 & 0 & 0\end{array}$

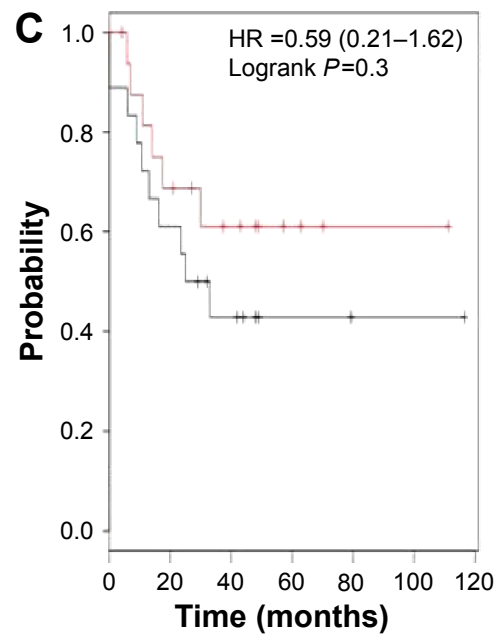

Number at risk

$\begin{array}{llllllll}\text { Low } & 18 & 11 & 6 & 2 & 1 & 1 & 0 \\ \text { High } & 18 & 11 & 7 & 3 & 1 & 1 & 0\end{array}$

\begin{tabular}{|l|}
\hline Expression \\
Low
\end{tabular} High

Figure $\mathbf{5}$ The prognostic value of ALDHILI expression.

Notes: The desired Affymetrix ID is valid: 205208_at (ALDHILI). Survival curves are plotted for $(\mathbf{A})$ all patients $(n=I, 306)$, $(\mathbf{B})$ serous cancer patients $(n=I, 019)$, and (C) endometrioid cancer patients $(n=36)$.

Abbreviations: ALDHI, aldehyde dehydrogenase I; HR, hazard ratio.

individual $A L D H 1$ except $A L D H 1 A 3$ is not significantly associated with pathological grades of ovarian cancer patients. ALDH1A3' high mRNA expression is associated with worse OS in grade II ovarian cancer patients, HR 1.53 (1.14-2.07), $P=0.005$. As observed in Table 2, all the individual $A L D H 1$ is not significantly associated with clinical stages of ovarian

Table I Correlation of ALDHI isoenzymes with pathological grades of ovarian cancer patients as a result of Kaplan Mier analysis

\begin{tabular}{lllll}
\hline Isoenzymes & $\begin{array}{l}\text { Pathological } \\
\text { grades }\end{array}$ & Cases & HR (95\% CI) & P-value \\
\hline ALDHIAI & I & 37 & $0.8(0.27-2.38)$ & 0.68 \\
& II & 247 & 1.1 I (0.82-I.49) & 0.5 \\
& III & 790 & $0.87(0.73-1.04)$ & 0.12 \\
ALDHIA2 & I & 37 & $1.55(0.5-4.76)$ & 0.44 \\
& II & 247 & $1.21(0.9-1.63)$ & 0.21 \\
& III & 790 & $1.14(0.96-1.35)$ & 0.14 \\
ALDHIA3 & I & 37 & $1.17(0.39-3.5)$ & 0.77 \\
& II & 247 & $1.53(1.14-2.07)$ & 0.005 \\
& III & 790 & $1.08(0.91-1.29)$ & 0.37 \\
ALDHIBI & I & 37 & $1.69(0.55-5.17)$ & 0.36 \\
& II & 247 & $1.19(0.88-1.6)$ & 0.26 \\
& III & 790 & $1.09(0.92-1.29)$ & 0.33 \\
ALDHILI & I & 37 & $3.28(0.9-11.95)$ & 0.056 \\
& II & 247 & $1.12(0.83-1.5 I)$ & 0.45 \\
& III & 790 & I (0.84-I.19) & 0.99 \\
\hline
\end{tabular}

Abbreviations: ALDHI, aldehyde dehydrogenase I; HR, hazard ratio; $\mathrm{Cl}$, confidence interval. cancer patients. We find from Table 3 that $A L D H 1 A 2$ 's high mRNA expression is significantly associated with worse OS in TP53 wild-type ovarian cancer patients, HR 2.86 (1.56-5.08), $P=0.00036$. In addition, $A L D H 1 A 3$ 's high mRNA expression is significantly associated with better OS in TP53 wild-type ovarian cancer patients, HR $0.56(0.32-1.00), P=0.04$.

Table 2 Correlation of ALDHI isoenzymes with clinical stages of ovarian cancer patients as a result of Kaplan Mier analysis

\begin{tabular}{|c|c|c|c|c|}
\hline Isoenzymes & $\begin{array}{l}\text { Clinical } \\
\text { stages }\end{array}$ & Cases & HR (95\% Cl) & $P$-value \\
\hline \multirow[t]{3}{*}{ ALDHIAI } & $\mathrm{I}+\mathrm{II}$ & 126 & $0.59(0.32-1.09)$ & 0.087 \\
\hline & III & 846 & $0.99(0.84-1.16)$ & 0.88 \\
\hline & IV & 143 & I (0.67-I.5) & I \\
\hline \multirow[t]{3}{*}{ ALDHIA2 } & I+II & 126 & $1.66(0.9-3.07)$ & 0.1 \\
\hline & III & 846 & $1.05(0.9-1.24)$ & 0.54 \\
\hline & IV & 143 & I.18 (0.79-I.76) & 0.43 \\
\hline \multirow[t]{3}{*}{ ALDHIA3 } & $1+I I$ & 126 & $0.83(0.46-I .5 I)$ & 0.55 \\
\hline & III & 846 & I.16 (0.99-I.36) & 0.074 \\
\hline & IV & 143 & $0.96(0.64-1.44)$ & 0.85 \\
\hline \multirow[t]{3}{*}{ ALDHIBI } & $1+I I$ & 126 & $\mathrm{I} .8(0.98-3.3 \mathrm{I})$ & 0.054 \\
\hline & III & 846 & $1.02(0.87-1.2)$ & 0.82 \\
\hline & IV & 143 & $0.87(0.58-|.3|)$ & 0.51 \\
\hline \multirow[t]{3}{*}{ ALDHILI } & $\mathrm{I}+\mathrm{II}$ & 126 & $0.73(0.4-1.32)$ & 0.29 \\
\hline & III & 846 & I.08 (0.92-I.27) & 0.35 \\
\hline & IV & 143 & I.0I (0.68-I.52) & 0.94 \\
\hline
\end{tabular}

Abbreviations: ALDHI, aldehyde dehydrogenase I; HR, hazard ratio; $\mathrm{Cl}$, confidence interval. 
Table 3 Correlation of ALDHI isoenzymes with TP53 mutation status of ovarian cancer patients as a result of Kaplan Mier analysis

\begin{tabular}{lllll}
\hline Isoenzymes & $\begin{array}{l}\text { TP53 } \\
\text { mutation }\end{array}$ & Cases & HR $(\mathbf{9 5} \% \mathbf{C I})$ & P-value \\
& No & 76 & $0.95(0.54-1.66)$ & 0.85 \\
ALDHIAI & Yes & 416 & $0.93(0.73-1.04)$ & 0.58 \\
& No & 76 & $2.82(1.56-5.08)$ & 0.00036 \\
ALDHIA2 & Yes & 416 & $0.91(0.7 I-I .17)$ & 0.48 \\
& No & 76 & $0.56(0.32-1)$ & 0.046 \\
ALDHIBI & Nes & 416 & $0.98(0.77-1.26)$ & 0.9 \\
& Yes & 76 & $0.99(0.56-1.75)$ & 0.99 \\
ALDHILI & No & 716 & $0.94(0.74-1.21)$ & 0.65 \\
& Yes & 416 & $0.91(0.5 I-1.63)$ & 0.75 \\
& & $0.78(0.6 I-1.01)$ & 0.055 \\
\hline
\end{tabular}

Abbreviations: $\mathrm{ALDHI}$, aldehyde dehydrogenase I; $\mathrm{HR}$, hazard ratio; $\mathrm{Cl}$, confidence interval.

\section{Discussion}

A number of previous studies focused on the relationship between ALDH1A1 protein expression and the clinicopathologic parameters, including prognosis of tumor patients. In most types of tumors, such as lung cancer, ${ }^{43}$ colorectal carcinoma, ${ }^{44}$ clear cell renal cell carcinoma ${ }^{45}$ esophageal squamous cell carcinoma, ${ }^{46}$ breast cancer, ${ }^{8,47,48}$ gastric cancer, ${ }^{49}$ head and neck cancer, ${ }^{50}$ and bladder cancer, ${ }^{51}$ high expression of ALDH1A1 protein was associated with tumor progression, metastasis, and poor prognosis. In contrast to the earlier studies, there were also a few reports showing that ALDH1A1 is a better prognostic marker in patients suffering from primary glioblastoma. ${ }^{52}$ In an early report, Chang et $\mathrm{al}^{20}$ observed that in contrast to its function in breast cancer, ALDH1A1 is a favorable prognostic factor in ovarian carcinoma. They believe that ALDH1A1, therefore, may have a different function in ovarian cancer than it does in breast cancer. However, Liebscher et al ${ }^{18}$ revealed that ALDH1A1, together with epidermal growth factor receptor coexpression, is a characteristic of a highly aggressive, poorprognosis subgroup of high-grade serous ovarian carcinoma. However, in a recent study, Huang et $\mathrm{a}^{15}$ still consider that high expression of ALDH1A1 in ovarian carcinoma cells may thus portend a favorable prognosis, but its expression in tumor microenvironment may have no role in tumor behavior of ovarian carcinomas. They suggest that more studies are warranted to find out the mechanisms for this.

The prognostic role of ALDH1 isoenzyme mRNA in ovarian cancer patients was not reported. We found that five ALDH1 isoenzymes', such as ALDH1A1, ALDH1A2, $A L D H 1 A 3, A L D H 1 B 1$, and $A L D H 1 L 1$, high mRNA expression was not to be correlated with OS for all ovarian cancer patients. In addition, all five of the ALDH1 isoenzymes' high mRNA expression was not found to be correlated with OS in serous cancer and endometrioid cancer patients. However, ALDH1A3's high mRNA expression is associated with worse OS in grade II ovarian cancer patients, HR 1.53 (1.14-2.07), $P=0.005$. ALDH1A2's high mRNA expression is significantly associated with worse OS in TP53 wild-type ovarian cancer patients, HR 2.86 (1.56-5.08), $P=0.00036$. In addition, $A L D H 1 A 3$ 's high mRNA expression is significantly associated with better OS in TP53 wild-type ovarian cancer patients, HR $0.56(0.32-1.00), P=0.04$. ALDH1L2 is expressed in the brain, heart, liver, kidney, and pancreas tissues by using real-time polymerase chain reaction performed on an array of human tissues, and no information is available for its expression in ovarian tissues. ${ }^{53}$ No survival information for ALDH1L2 in ovarian cancer patients is available, probably due to its low expression in normal ovarian tissue and ovarian cancer.

There are strong evidences showing the correlation between $\mathrm{p} 53$ function and ovarian cancer stem cells. Kurrey et al reported that snail and slug mediate radioresistance and chemoresistance by antagonizing p53-mediated apoptosis and acquiring a stem-like phenotype in ovarian cancer cells. ${ }^{54}$ Motohara et al also observed that transient depletion of p53 followed by transduction of c-Myc and KRas converts ovarian stem-like cells into cancer stem cells. ${ }^{55}$ Interestingly, ovarian cancer cells display long-term stem cell properties ex vivo and in vivo and express stem and/or progenitor cell markers, ALDH1, LGR5, LEF1, CD133, and CK6B, after inactivation of tumor suppressor genes TP53 and $\mathrm{RB} 1 .{ }^{56}$ In our results, we find that $A L D H 1 A 2$ 's high mRNA expression is significantly associated with worse OS in TP53 wild-type ovarian cancer patients. In contrast, $A L D H 1 A 3$ 's high mRNA expression is significantly associated with better OS in TP53 wild-type ovarian cancer patients. The significance of correlation between p53 and individual ALDH1 isoenzymes in ovarian cancer needs further study.

ALDH1 belongs to a family of detoxifying enzymes that convert aldehydes to their corresponding carboxylic acids, and members of this family are present in many types of normal tissues. ${ }^{57,58}$ Currently, the "gold standard" of the measurement of ALDH1's activity in viable cells is measured by the use of flow cytometry and fluorescent substrates for ALDH1 ${ }^{8,59,60}$ It is not clear about the role of each ALDH1 isoenzyme that contributes to ALDH1 activity in ovarian cancer cells. It will be helpful to know which ALDH1 isoenzyme contributes to ALDH1 activity if we measure the changes in ALDH1 activity upon using small interfering RNAs or antibodies of individual ALDH1 isoenzymes in 
ovarian cancer cells. Our current study found that unlike breast cancer, ALDH1A1 mRNA in ovarian cancer is not associated with poor prognosis. Our current study supports that ALDH1A2 and ALDH1A3 might be major contributors to the ALDH1 activity in ovarian cancer, since $A L D H 1 A 2$ and ALDH1A3's high mRNA expression was found to be significantly correlated with worse OS for some type of ovarian cancer patients. The analysis of ALDH1A1 expression will also be important for the design of treatment and the assessment of the prognosis of ovarian cancer patients by using high-quality commercial antibodies against ALDH1A1.

Please note that $A L D H 1$ mRNA was extracted from cancer tissues, which were composed of many type of cells, such as different types of stromal cells and epithelial cells. Thus, ALDH1 isoenzymes' mRNA expression in the individual cell types may be different. In a recent report, Isfoss et $\mathrm{al}^{61}$ analyzed immunohistologically for the stem cell marker, ALDH1A1, in different forms of bladder neoplasia and observed that the majority of stem cell marker-positive cells were located in the connective tissue and a smaller fraction in the epithelial tissue. Stem cell marker-positive cells with nonstem cell character included stellate cells, mast cells, endothelial cells, foamy histiocytes, and neurons. Therefore, it is interesting to further study the role and clinical significance of the individual ALDH1 isoenzymes in different types of cells.

\section{Disclosure}

The authors have no financial involvement with any organization or entity with a financial interest in the subject matter or materials discussed in the manuscript. The authors reported no conflicts of interest in this work.

\section{References}

1. Ovarian Cancer National Alliance [webpage on the Internet]. Learn About the Subtypes of Ovarian Cancer and Key Facts about This Disease. 2013. Available from: http://www.ovariancancer.org/about-ovarian-cancer/ statistics/. Accessed February 24, 2016.

2. Leung PC, Choi JH. Endocrine signaling in ovarian surface epithelium and cancer. Hum Reprod Update. 2007;13:143-162.

3. Foley OW, Rauh-Hain JA, del Carmen MG. Recurrent epithelial ovarian cancer: an update on treatment. Oncology (Williston Park). 2013; 27(288-294):98.

4. Coleman RL, Monk BJ, Sood AK, Herzog TJ. Latest research and treatment of advanced-stage epithelial ovarian cancer. Nat Rev Clin Oncol. 2013;10:211-224.

5. Vasiliou V, Thompson DC, Smith C, Fujita M, Chen Y. Aldehyde dehydrogenases: from eye crystallins to metabolic disease and cancer stem cells. Chem Biol Interact. 2013;202:2-10.

6. Muzio G, Maggiora M, Paiuzzi E, Oraldi M, Canuto RA. Aldehyde dehydrogenases and cell proliferation. Free Radic Biol Med. 2012;52: 735-746.

7. Pearce DJ, Taussig D, Simpson C, et al. Characterization of cells with a high aldehyde dehydrogenase activity from cord blood and acute myeloid leukemia samples. Stem Cells. 2005;23:752-760.
8. Ginestier C, Hur MH, Charafe-Jauffret E, et al. ALDH1 is a marker of normal and malignant human mammary stem cells and a predictor of poor clinical outcome. Cell Stem Cell. 2007;1:555-567.

9. Balicki D. Moving forward in human mammary stem cell biology and breast cancer prognostication using ALDH1. Cell Stem Cell. 2007;1: 485-487.

10. Young MJ, Wu YH, Chiu WT, Weng TY, Huang YF, Chou CY. All-trans retinoic acid downregulates ALDH1-mediated stemness and inhibits tumour formation in ovarian cancer cells. Carcinogenesis. 2015;36: 498-507.

11. Mizuno T, Suzuki N, Makino H, et al. Cancer stem-like cells of ovarian clear cell carcinoma are enriched in the ALDH-high population associated with an accelerated scavenging system in reactive oxygen species. Gynecol Oncol. 2015;137:299-305.

12. Han X, Du F, Jiang L, et al. A2780 human ovarian cancer cells with acquired paclitaxel resistance display cancer stem cell properties. Oncol Lett. 2013;6:1295-1298.

13. Kuroda T, Hirohashi Y, Torigoe T, et al. ALDH1-high ovarian cancer stem-like cells can be isolated from serous and clear cell adenocarcinoma cells, and ALDH1 high expression is associated with poor prognosis. PLoS One. 2013;8:e65158.

14. Deng S, Yang X, Lassus H, et al. Distinct expression levels and patterns of stem cell marker, aldehyde dehydrogenase isoform 1 (ALDH1), in human epithelial cancers. PLoS One. 2010;5:e10277.

15. Huang R, Li X, Holm R, Trope CG, Nesland JM, Suo Z. The expression of aldehyde dehydrogenase 1 (ALDH1) in ovarian carcinomas and its clinicopathological associations: a retrospective study. BMC Cancer. 2015;15:502.

16. Sun Y, Jia X, Wu X. High expressions of Lgr5 and ALDH1 in primary epithelial ovarian cancer correlate with advanced tumor stage and grade as well as poor prognosis of the patients. Gynecol Obstet Invest. 2015; 20:20.

17. Ayub TH, Keyver-Paik MD, Debald M, et al. Accumulation of ALDH1positive cells after neoadjuvant chemotherapy predicts treatment resistance and prognosticates poor outcome in ovarian cancer. Oncotarget. 2015;6:16437-16448.

18. Liebscher CA, Prinzler J, Sinn BV, et al. Aldehyde dehydrogenase 1/epidermal growth factor receptor coexpression is characteristic of a highly aggressive, poor-prognosis subgroup of high-grade serous ovarian carcinoma. Hum Pathol. 2013;44:1465-1471.

19. Wang YC, Yo YT, Lee HY, et al. ALDH1-bright epithelial ovarian cancer cells are associated with CD44 expression, drug resistance, and poor clinical outcome. Am J Pathol. 2012;180:1159-1169.

20. Chang B, Liu G, Xue F, et al. ALDH1 expression correlates with favorable prognosis in ovarian cancers. Mod Pathol. 2009;22:817-823.

21. Douville J, Beaulieu R, Balicki D. ALDH1 as a functional marker of cancer stem and progenitor cells. Stem Cells Dev. 2009;18:17-25.

22. Ma I, Allan AL. The role of human aldehyde dehydrogenase in normal and cancer stem cells. Stem Cell Rev. 2011;7:292-306.

23. Ehlers CL. Variations in ADH and ALDH in Southwest California Indians. Alcohol Res Health. 2007;30:14-17.

24. Gyorffy B, Lanczky A, Eklund AC, et al. An online survival analysis tool to rapidly assess the effect of 22,277 genes on breast cancer prognosis using microarray data of 1,809 patients. Breast Cancer Res Treat. 2010;123:725-731.

25. Gyorffy B, Benke Z, Lanczky A, et al. RecurrenceOnline: an online analysis tool to determine breast cancer recurrence and hormone receptor status using microarray data. Breast Cancer Res Treat. 2012;132: 1025-1034.

26. Gyorffy B, Lanczky A, Szallasi Z. Implementing an online tool for genome-wide validation of survival-associated biomarkers in ovariancancer using microarray data from 1287 patients. Endocr Relat Cancer. 2012;19:197-208.

27. Liu M, Wang G, Gomez-Fernandez CR, Guo S. GREB1 functions as a growth promoter and is modulated by IL6/STAT3 in breast cancer. PLoS One. 2012;7:e46410. 
28. Tilghman SL, Townley I, Zhong Q, et al. Proteomic signatures of acquired letrozole resistance in breast cancer: suppressed estrogen signaling and increased cell motility and invasiveness. Mol Cell Proteomics. 2013;12:2440-2455.

29. Zhou C, Zhong Q, Rhodes LV, et al. Proteomic analysis of acquired tamoxifen resistance in MCF-7 cells reveals expression signatures associated with enhanced migration. Breast Cancer Res. 2012;14:R45.

30. Maciejczyk A, Szelachowska J, Czapiga B, et al. Elevated BUBR1 expression is associated with poor survival in early breast cancer patients: 15-year follow-up analysis. J Histochem Cytochem. 2013;61: 330-339.

31. Maciejczyk A, Lacko A, Ekiert M, et al. Elevated nuclear S100P expression is associated with poor survival in early breast cancer patients. Histol Histopathol. 2013;28:513-524.

32. Maciejczyk A, Jagoda E, Wysocka T, et al. ABCC2 (MRP2, cMOAT) localized in the nuclear envelope of breast carcinoma cells correlates with poor clinical outcome. Pathol Oncol Res. 2012;18:331-342.

33. Adam MA. New prognostic factors in breast cancer. Adv Clin Exp Med. 2013;22:5-15.

34. Ivanova L, Zandberga E, Silina K, et al. Prognostic relevance of carbonic anhydrase IX expression is distinct in various subtypes of breast cancer and its silencing suppresses self-renewal capacity of breast cancer cells. Cancer Chemother Pharmacol. 2015;75:235-246.

35. Wu S, Xue W, Huang X, et al. Distinct prognostic values of ALDH1 isoenzymes in breast cancer. Tumour Biol. 2015;13:13.

36. Hong CQ, Zhang F, You YJ, et al. Elevated C1orf63 expression is correlated with $\mathrm{CDK} 10$ and predicts better outcome for advanced breast cancers: a retrospective study. BMC Cancer. 2015;15:548.

37. Ortega CE, Seidner Y, Dominguez I. Mining CK2 in cancer. PLoS One. 2014;9:e115609.

38. Gyorffy B, Surowiak P, Budczies J, Lanczky A. Online survival analysis software to assess the prognostic value of biomarkers using transcriptomic data in non-small-cell lung cancer. PLoS One. 2013;8: e82241.

39. You Q, Guo H, Xu D. Distinct prognostic values and potential drug targets of ALDH1 isoenzymes in non-small-cell lung cancer. Drug Des Devel Ther. 2015;9:5087-5097.

40. Dotsch MM, Kloten V, Schlensog M, et al. Low expression of ITIH5 in adenocarcinoma of the lung is associated with unfavorable patients' outcome. Epigenetics. 2015;10:903-912.

41. Kamieniak MM, Rico D, Milne RL, et al. Deletion at 6q24.2-26 predicts longer survival of high-grade serous epithelial ovarian cancer patients. Mol Oncol. 2015;9:422-436.

42. Gayarre J, Kamieniak MM, Cazorla-Jimenez A, et al. The NER-related gene GTF2H5 predicts survival in high-grade serous ovarian cancer patients. J Gynecol Oncol. 2015;12:12.

43. Jiang F, Qiu Q, Khanna A, et al. Aldehyde dehydrogenase 1 is a tumor stem cell-associated marker in lung cancer. Mol Cancer Res. 2009;7: $330-338$.

44. Xu SL, Zeng DZ, Dong WG, et al. Distinct patterns of ALDH1A1 expression predict metastasis and poor outcome of colorectal carcinoma. Int J Clin Exp Pathol. 2014;7:2976-2986.

45. Wang K, Chen X, Zhan Y, et al. Increased expression of ALDH1A1 protein is associated with poor prognosis in clear cell renal cell carcinoma. Med Oncol. 2013;30:574.

OncoTargets and Therapy

\section{Publish your work in this journal}

OncoTargets and Therapy is an international, peer-reviewed, open access journal focusing on the pathological basis of all cancers, potential targets for therapy and treatment protocols employed to improve the management of cancer patients. The journal also focuses on the impact of management programs and new therapeutic agents and protocols on
46. Yang L, Ren Y, Yu X, et al. ALDH1A1 defines invasive cancer stem-like cells and predicts poor prognosis in patients with esophageal squamous cell carcinoma. Mod Pathol. 2014;27:775-783.

47. Mieog JS, de KEM, Bastiaannet E, et al. Age determines the prognostic role of the cancer stem cell marker aldehyde dehydrogenase- 1 in breast cancer. BMC Cancer. 2012;12:42.

48. Neumeister V, Agarwal S, Bordeaux J, Camp RL, Rimm DL. In situ identification of putative cancer stem cells by multiplexing ALDH1, CD44, and cytokeratin identifies breast cancer patients with poor prognosis. Am J Pathol. 2010;176:2131-2138.

49. Li XS, Xu Q, Fu XY, Luo WS. ALDH1A1 overexpression is associated with the progression and prognosis in gastric cancer. BMC Cancer. 2014; $14: 705$

50. Xu J, Muller S, Nannapaneni S, et al. Comparison of quantum dot technology with conventional immunohistochemistry in examining aldehyde dehydrogenase $1 \mathrm{~A} 1$ as a potential biomarker for lymph node metastasis of head and neck cancer. Eur J Cancer. 2012;48:1682-1691.

51. Keymoosi H, Gheytanchi E, Asgari M, Shariftabrizi A, Madjd Z. ALDH1 in combination with CD44 as putative cancer stem cell markers are correlated with poor prognosis in urothelial carcinoma of the urinary bladder. Asian Pac J Cancer Prev. 2014;15:2013-2020.

52. Adam SA, Schnell O, Poschl J, et al. ALDH1A1 is a marker of astrocytic differentiation during brain development and correlates with better survival in glioblastoma patients. Brain Pathol. 2012;22:788-797.

53. Krupenko NI, Dubard ME, Strickland KC, Moxley KM, Oleinik NV, Krupenko SA. ALDH1L2 is the mitochondrial homolog of 10formyltetrahydrofolate dehydrogenase. J Biol Chem. 2010;285: 23056-23063.

54. Kurrey NK, Jalgaonkar SP, Joglekar AV, et al. Snail and slug mediate radioresistance and chemoresistance by antagonizing p53-mediated apoptosis and acquiring a stem-like phenotype in ovarian cancer cells. Stem Cells. 2009;27:2059-2068.

55. Motohara T, Masuko S, Ishimoto T, et al. Transient depletion of p53 followed by transduction of c-Myc and K-Ras converts ovarian stem-like cells into tumor-initiating cells. Carcinogenesis. 2011;32:1597-1606.

56. Flesken-Nikitin A, Hwang CI, Cheng CY, Michurina TV, Enikolopov G, Nikitin AY. Ovarian surface epithelium at the junction area contains a cancer-prone stem cell niche. Nature. 2013;495:241-245.

57. Vasiliou V, Pappa A, Petersen DR. Role of aldehyde dehydrogenases in endogenous and xenobiotic metabolism. Chem Biol Interact. 2000; 129:1-19.

58. Vasiliou V, Nebert DW. Analysis and update of the human aldehyde dehydrogenase (ALDH) gene family. Hum Genomics. 2005;2: $138-143$.

59. Burger PE, Gupta R, Xiong X, et al. High aldehyde dehydrogenase activity: a novel functional marker of murine prostate stem/progenitor cells. Stem Cells. 2009;27:2220-2228.

60. Chute JP, Muramoto GG, Whitesides J, et al. Inhibition of aldehyde dehydrogenase and retinoid signaling induces the expansion of human hematopoietic stem cells. Proc Natl Acad Sci U S A. 2006;103: 11707-11712.

61. Isfoss BL, Busch C, Hermelin H, et al. Stem cell marker-positive stellate cells and mast cells are reduced in benign-appearing bladder tissue in patients with urothelial carcinoma. Virchows Arch. 2014;464: 473-488.

\section{Dovepress}

patient perspectives such as quality of life, adherence and satisfaction The manuscript management system is completely online and includes a very quick and fair peer-review system, which is all easy to use. Visit http://www.dovepress.com/testimonials.php to read real quotes from published authors. 